\title{
Frequency of Cataract in Diabetic Verses Non-Diabetic Patients
}

\author{
Kiran Aslam, Muhammad Sufyan Aneeq Ansari, Imran Khalid, Khurram Nafees
}

Pak J Ophthalmol 2019, Vol. 35, No. 1

See end of article for authors affiliations

Correspondence to:

Kiran Aslam

Bsc.(Hons) Optometery \&

Orthoptics

Department of Ophthalmology,

Fatima Memorial Hospital

Lahore

Email:

kiranaslam1103@gmail.com
Purpose: To determine the frequency of cataract in diabetic verses non-diabetic patients.

Study Design: Descriptive cross-sectional study.

Place and Duration of Study: Eye Outpatients Department of Fatima Memorial Hospital Lahore from December to March 2018.

Material and Methods: Patients between 20-50 years of age with and without diabetes were included in the study. The diabetic patients included in the study had diabetes for at least 6-7 years. Patients with any other systemic disease and patients $<20$ years and $>50$ years were excluded from the study. All patients underwent a complete eye examination including uncorrected and best corrected visual acuity, refraction, dilated slit lamp and fundus examination.

Results: A total of 194 patients were examined. Average duration of diabetes was 6-7 years with age groups $20-35$ years $(34.02 \%)$ and $35-50$ years $(65.97 \%)$. There were $79(79.79 \%)$ patients with diabetes who had cataract while only 13 $(13.68 \%)$ non- diabetic patients had cataract. Most common type of cataract in diabetic patients was posterior subcapsular cataract (PSCC) $43(54.43 \%)$. This was followed by nuclear cataract in $17(21.51 \%)$ and cortical cataract in 14 $(17.72 \%)$ patients. While in non-diabetic patients nuclear cataract was seen in 6 (46.15\%) patients and cortical and PSCC were the same percentage $3(23.07 \%)$. Cataract frequently developed in the age group of 35-50 years in diabetic patients.

Conclusion: Diabetic patients should be screened for cataract early as PSCC can cause significant deterioration of vision between 35-50 years.

Keywords: Cataract, Diabetes Mellitus (DM), Posterior Sub Capsular Cataract (PSCC), Nuclear Cataract (NC) and Cortical Cataract (CC).
$\mathrm{A}$ ny opacity in the lens or in its capsule, either congenital or acquired, unilateral or bilateral is commonly called cataract ${ }^{1}$. Diabetes is characterized by fasting blood glucose level $<70 \mathrm{mg} / \mathrm{dL}^{2}$.

Cataract is the leading cause of blindness worldwide. It is 2-5 times more in diabetic patients ${ }^{3}$. Co-existence of cataract and diabetes mellitus results in overall $45 \%$ visual impairment ${ }^{4}$. In 2017, survey suggest that cataract was the predominant cause contributing to severe VI $(70 \%)$ and blindness $(57 \%)^{5}$. There is evidence that the risk of cataract increases with increasing duration of diabetes and severity of hyperglycemia ${ }^{6}$.Even though aging is another risk factor for development of cataract, while nutritional deficiencies, trace metals, exposure to sunlight, smoking are also responsible for development of cataract ${ }^{7}$.

According to WHO (World Health Organization) meaning of blindness is "visual acuity of $<3 / 60$ using Snellen chart with the best possible correction \& visual field less than 10 degree". In 2002, WHO enlisted the cataract was one of the top leading cause of blindness. It was presented as $47.9 \%$ cataract and $4.8 \%$ diabetic 
retinopathy. In Pakistan, national survey on blindness reported in 2004-5, which concluded that 53\% cataract, $11 \%$ cataract related like aphakia and PCO and $<0.5 \%$ diabetes related blindness existed. Vision 2020 is worldwide activity to take out primary driver of all preventable and treatable visual impairment continuously 2020 ${ }^{\circ}$. Predominance of visual impairment was higher because of cataract in Punjab territory of Pakistan, particularly in rustic zones and uneducated individuals. The predominance of cataract was higher in ladies than men $(1.80 \%$ versus $1.67 \%$, $\mathrm{p}<0.001)$. There are around 570000 grown-ups $(225$ 000 men and 345000 ladies) who are visually impaired from cataract in Pakistan, which will be increment to 1 210000 continuously $2020 .{ }^{9}$ Pervasiveness of cataract causing $<6 / 60$ in eyes was $5.0 \%$, around 3560000 eyes in Pakistan (year 2003). The number is anticipated to increment to 7380000 continuously 2020. Around 2 million individuals are visually impaired in Pakistan. Cataract is in charge of $66.7 \%$ visual impairment in Pakistan $^{10}$.

In Pakistan 6.9 million individual are affected by diabetes. With the international diabetes federation evaluating that this number will develop to 11.5 million by 2025 unless measures are taken to control the susceptive disorders. This is the principle explanation behind profoundly required pharmacological intercession that will keep up the transparency of lens; it is assessed that a deferral in cataract development of around 10 years would diminish the commonness of outwardly incapacitating cataract by around $45 \%{ }^{11}$.

Dominant part of cataract patient's vision could be reestablished to an attractive level by carefully expelling the lens and substituting it with a lens made of manufactured polymers ${ }^{12}$.Phacoemulsification is protected and successful method with great visual result whenever performed in experienced hands under fastidious sterilization and aseptic measures. ${ }^{13}$ The rate of cataract is large to the point that medical procedure alone has been discovered insufficient in tackling this issue. Diabetic patient must need observing of fundus consistently after at regular intervals ${ }^{12}$.

\section{MATERIAL AND METHODS}

This is descriptive cross-sectional study included 194 diabetic and non-diabetic patients randomly presented in the medical OPD of Fatima Memorial Hospital in 2017. Eligibility criteria were as followed: age between
20-50 years old, diabetic patients with at least 6-7 year duration of diabetes. The duration of diabetes was taken as the period from the diagnosis of DM to the day of examination for cataract surgery as informed by the patient. The patients with age $<20$ and $>50$ were excluded in this study. The capacity to give data about vision and consent to answer a survey about socioeconomics, diabetic entanglements and other restorative determination and medicines utilized. In the wake of taking patient's consent and noting the survey all subjects underwent a complete eye examination, including uncorrected and best corrected visual acuity, refraction, dilated slit lamp and fundus examination. Individual with any other systemic and ocular diseases were excluded. After taking patient's history, subjects were classified into diabetic and nondiabetic, diagnosis made by general physician. Visual examination including visual acuity \& pinhole testing was done monocularly at six meter distance using snellen chart. An improvement of visual acuity with pinhole was considered refractive error and visual acuity of $\leq 6 / 12$ was regarded as reduced vision. Patient's visual assessment data was recorded on well defined proforma. After taking consent patient was dialated with tropicamide (Mydriacyl 1\%) and were examined by ophthalmologist to decide the presence and absence of cataract and the type of cataract using a slit lamp. The following variables were assessed; presence of diabetes, presence of cataract and type of cataract. Pearson's chi square test was utilized for catagorical factors. The $\mathrm{p}$ value was viewed as noteworthy if $\mathrm{p}$-value $<0.05$. After examination, diabetic patients with cataract were referred to ophthalmologist for monitoring impacts of cataract on vision, make regular follow-ups to monitor the fundus for diabetic retinopathy and for surgical plan in correspondence to cataract severity.

\section{RESULTS}

The data was entered and analyzed in SPSS 20.0 version. All quantitative variables age distribution was discussed in Mean \pm standard deviation form. All qualitative variables like gender, diabetes, cataract and its type was discussed in frequency or percentage form.

In this study, one hundred and ninety-four $(n=194)$ patients were enrolled including diabetic and non-diabetic patients. In both genders, the prevalence of cataract was found to be decreased initially by 
Table 1: Distribution of Cataract in Subjects.

\begin{tabular}{|lcccc|}
\hline & Presence of Cataract & Absence of Cataract & Total & P-Value \\
\hline Subjects & $92(47.4 \%)$ & $102(52.6 \%)$ & 194 & \\
Male & $29(38.66 \%)$ & $46(16.33 \%)$ & 75 & $0.036^{*}$ \\
Female & $63(52.94 \%)$ & $56(47.05 \%)$ & 119 & $0.000^{*}$ \\
Age $(20-35)$ & $6(9.1 \%)$ & $60(90.9 \%)$ & 66 & 128 \\
\hline
\end{tabular}

Table 2: Relative risk of Cataract in Diabetics verses Non-Diabetics

\begin{tabular}{|c|c|c|c|c|c|c|}
\hline Cataract & Diabetic & Non- Diabetic. & & Total & P-Value & \\
\hline Present & $79(85.9 \%)$ & $13(14.1 \%)$ & 92 & & & \\
\hline Absent & $20(19.6 \%)$ & $82(80.4 \%)$ & 102 & $0.001^{*}$ & $58(87.9 \%)$ & 66 \\
\hline $\begin{array}{ll}\text { Age } & (20-35) \\
(36-50)\end{array}$ & $\begin{array}{r}8(12.1 \%) \\
91(71.1 \%)\end{array}$ & $37(28.9 \%)$ & 128 & & & \\
\hline Total & 99 & 95 & & & & \\
\hline
\end{tabular}

group 20-35 years and then increased in $\geq 40$ years group. Cataract is more typical in female when contrasted with male as appeared in table: 1 by applying chi square test outcomes were critical with $\mathrm{p}$ value $<0.05$.

Frequency of cataract in diabetic patients with age groups shown in the table 2 .

Table 3: Distribution of Cataract Type in Diabetics verses Non-Diabetics

\begin{tabular}{|lcc|}
\hline Type of Cataract & Diabetic & Non-Diabetic \\
\hline PSCC & $43(54.43 \%)$ & $3(23.07 \%)$ \\
Early lenticular changes & $5(6.32 \%)$ & $1(7.69 \%)$ \\
Nuclear Cataract & $17(21.51 \%)$ & $6(46.15 \%)$ \\
Cortical Cataract & $14(17.72 \%)$ & $3(23.07 \%)$ \\
Total & $79(100.0 \%)$ & $13(100.0 \%)$ \\
\hline
\end{tabular}

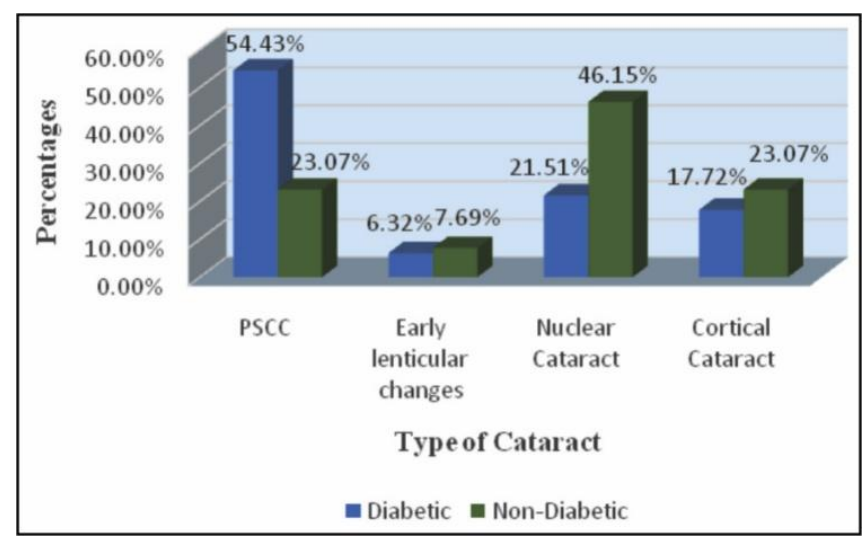

Graph 1: Type of Cataract in Diabetic and NonDiabetic Patients.
Presence of diabetes and cataract is shown in the table 2 by applying chi square test result showed that Diabetes is significantly associated with cataract with $\mathrm{P}$ value 0.001 at $5 \%$ margin of error with $95 \%$ confidence interval. The outcomes were critical with $\mathrm{p}$ value $<0.05$.

Table 3 shows; out of 99 diabetic patients, the most common type of cataract was PSCC 43 (54.43\%).

Out of 95 non-diabetic patients, the most common type was nuclear cataract $6(46.15 \%)$ as shown in table 3.

\section{DISCUSSION}

Duration of diabetes and age is a hazard factor for advancement of cataract in diabetic patients. Charles et al. examine in 2003 in which normal term of diabetes was 7 years and the time of diagnosis was 46.5 years. ${ }^{14}$ While in present examination, the span of diabetes was 6-7 years. Although in present study age was classified into two groups 20-35 \&36-50 years. Results showed that subjects in 20-35 years, 6 (9.1\%) had cataract. While subjects in $36-50$ years, 86 (67.2\%) were presented with cataract including diabetic and non-diabetic. Cataract was more in age between 36-50 years. Thus, result of both studies are almost equal.

In 2003 Charles et al. reported prevalence of cataract $44.9 \%$ in West African type 2 diabetic patients which is almost half as compared to in our population ${ }^{14}$.In present study diabetic cataract was present in 79 (85.9\%) and absent in 20 (19.6\%). Although in non-diabetic patients cataract was present in $13(14.1 \%)$ and absent in $82(80.4 \%)$ patients. 
Diabetes is the major risk factor for cataract.

When considering the higher prevalence of diabetes mellitus in females, it follows that the incidence of diabetic cataract would be higher in females than male. Sung et al.in 2006 reported that two groups of diabetic patients, one was control group and the other was cataract group. The author (s) concluded that females were more common in cataract group than control group. ${ }^{12}$ Similar to present study in which prevalence of diabetes and cataract was more in females than male. Out of 194 patients 63 (52.94\%) females and 29 (38.66) male were presented with cataract. In term of relationship between diabetes and gender, the increased incidence of diabetic cataract were appeared in females.

In 2012 Eydis conducted study on prevalence of cataract in a population with and without type 2 diabetes mellitus. According to author 274 patients were diagnosed with diabetes and 256 controlled. Three types of cataract was observed $65.5 \%$ cortical, $42.5 \%$ PSCC and $48 \%$ nuclear cataract in type 2 diabetes ${ }^{15}$.Similarly to compare most recent studies, Patricia et al. conducted study in 2017 on pre-senile cataract in diabetic Patients. The hypothesis of Patricia was a cortical cataract is more common in diabetic population. Patricia looked at the discoveries of best quality level LOCS III (lens opacity classification system III) with scheimpflug target measures in a presenile population. Author(s) concluded that out of 43 diabetic patients $88.4 \%$ were having sub capsular cataract, $52.3 \%$ cortical and $7 \%$ nuclear cataract that is twice as compared to present study ${ }^{16}$. While in 2010 Rajiv Raman concluded that among the monotype cataracts, CC was the most common subtype in patients with type $2 \mathrm{DM}(15.1 \%)$. In the mixed cataracts, the combination of NC, CC, and PSC was the most common $(19.5 \%)^{17}$.

Results of present study shows for diabetic as well as for non-diabetic patients. It shows significant association between diabetes and PSCC. In this study 43 (54.43\%) PSCC, 14 (17.72\%) cortical and 17 (21.51\%) nuclear cataract in diabetic patients that was definitely higher than previous study. While in non-diabetic patients 3 (23.07\%) were present with PSCC, 1 (7.69\%) present with early lenticular changes, 6 (46.15\%) present with nuclear cataract and cortical cataract was 3 (23.07\%).Subsequently, early improvement of pharmacological and careful methods for cataract anticipation ought to be one of the fundamental needs for future cataract examine. These intercessions must encouraging to overcome the expanding pervasiveness of cataract in diabetic patients ${ }^{18}$.

Currently the only available treatment for disease is surgical removal of opaque lens and followed by replacement with synthetic implants. Efforts have been taken to explore the traditional medicine to delay and retard the progression of cataract. Several numbers of plants and synthetic compounds has been reported to possess anti-cataract activity. ${ }^{19}$ Success rate of cataracts surgery, without serious complications and improved vision is possible with the advanced surgical procedure and with the aid of equipment's. ${ }^{20}$ However, most common side effects reported in the post-surgical treatment was inflammatory reaction and cystoid macular oedema ${ }^{21}$.

\section{CONCLUSION}

Cataract was present $79 \%$ in defined population. This study shows that there is high frequency of cataract in diabetic patients which can be avoided its consequences delayed if they are timely referred to ophthalmologist to diagnose and manage early for better visual outcomes.

\section{ACKNOWLEDGMENT}

I paid my tributes and thank to Miss Tayyaba Rahat for encouragement and support from the initial to the final level of this work. Special thank for helping me in statistical analysis.

\section{Conflict of Interest}

Approved by ethical committee \& IRB of institute.

\section{Funding Sources}

Self-funded Hospital data was used.

\section{Authors Affiliation}

Kiran Aslam

Bsc.(Hons) Optometery \& Orthoptics

FMH College of Medicine \& Dentistry

Dr. Muhammad Sufyan Aneeq Ansari

Assistant Professor of Ophthalmology

Fatima Memorial Hospital Lahore

Imran Khalid

Orthoptist BSVS, M.phil (Sch), CRCP

Services Hospital Lahore 
Dr. Khurram Nafees

Assistant Professor of Ophthalmology,

Fatima Memorial Hospital Lahore

\section{Author's Contribution}

Kiran Aslam

Substantial Contribution in conception, designing, acquisition, analysis or interpretation of data.

Dr. Muhammad Sufyan Aneeq Ansari

Final approval of manuscript.

Imran Khalid

Manuscript drafting \& revision for intellectual content.

Dr. Khurram Nafees

Contribution in conception \& designing of manuscript.

\section{REFERENCES}

1. Kanski JJ. Clinical ophthalmology. 8th ed. Vol. 1. NewSouth Wales, Australia: Butterworths, 1989: 270300.

2. Thomson William. Diseases of The Eye. 4th ed. Vol. 1. S.l: Hansebooks, 2016: 110-114.

3. Lathika V, Ajith T. Association of grade of cataract with duration of diabetes, age and gender in patients with type II diabetes mellitus. International Journal of Advances in Medicine, 2016; (1): 304-8.

4. Gupta S, Selvan V, Agrawal S, Saxena R. Advances in pharmacological strategies for the prevention of cataract development. Indian Journal of Ophthalmology, 2009, 57(3):175.

5. Open Access Research Prevalence and causes of visual... [Internet].[cited 2018Oct14].Availablefrom:https://bmjopen.bmj.com/c ontent/bmjopen/8/3/e018894.full.pdf

6. Negahban $K$, Chern K. Cataracts associated with systemic disorders and syndromes. Current Opinion in Ophthalmology, 2002; 13(6):419-22.

7. Patel PM, Jivani N, Malaviya S, Gohil T, Bhalodia Y. Cataract: A major secondary diabetic complication. International Current Pharmaceutical Journal, 2012; Mar 1(7): 3-57.

8. Jatoi SM. Clinical ophthalmology. 5th ed. Vol. 1. Karachi,, Pakistan: Paramount Books; 2013: 269-272.

9. Dineen B, Bourne RRA, Jadoon Z, Shah SP, Khan MA, Foster A, et al. Causes of blindness and visual impairment in Pakistan. The Pakistan national blindness and visual impairment survey. British Journal of Ophthalmology, 2007; 91(8):1005-10.

10. Jadoon Z, Shah S, Bourne R, Dineen B, Khan M, Gilbert $C$ et al. Cataract prevalence, cataract surgical coverage and barriers to uptake of cataract surgical services in Pakistan: the Pakistan National Blindness and Visual Impairment Survey. British Journal of Ophthalmology, 2007; 91(10):1269-1273.

11. Marathe PH, GAOHX, Close KL. American Diabetes Association Standards of Medical Care in Diabetes2017.Journal of Diabetes, 2017; 9(4):320-4.

12. Kim SI, Kim SJ. Prevalence and Risk Factors for Cataracts in Persons with Type 2 Diabetes Mellitus. Korean Journal of Ophthalmology, 2006; 20(4):201.

13. Visual Outcome of Cataract Surgery after Phacoemulsification [Internet]. [Cited 2018Oct15]. Available from: http://www.pjo.com.pk/33/4/9. Sanaullah - MM31Dec.pdf

14. Rotimi C, Daniel H, Zhou J, et al. Prevalence and determinants of diabetic retinopathy and cataracts in West African type 2 diabetes patients. Ethn Dis 2003; 13(2 Suppl 2): S110-7. 22

15. Olafsdottir E, Andersson DKG, Stefánsson E. The prevalence of cataract in a population with and without type 2 diabetes mellitus. ActaOphthalmologica.2011; 90(4):334-40.

16. Kyselova Z, Stefek M, Bauer V. Pharmacological prevention of diabetic cataract. Journal of Diabetes and its Complications, 2004; 18(2):129-40.

17. Raman R, Pal SS, Adams JSK, Rani PK, Vaitheeswaran K, Sharma T. Prevalence and Risk Factors for Cataract in Diabetes: Sankara Nethralaya Diabetic Retinopathy Epidemiology and Molecular Genetics Study, Report No. 17. Invest Opthalmol \& Vis Sci. 2010; 51(12):6253.

18. Rooban BN, Sasikala V, Sahasranamam V, Abraham A. Vitexnegundo Modulates Selenite-Induced Opacification and Cataractogensis in Rat Pups. Biological Trace Element Research, 2010; 138(1-3):28292.

19. Dowler JG, Hykin PG, Hamilton AM. Phacoemulsification versus extracapsular cataract extraction in patients with diabetes. Ophthalmol. 2000; 107(3):457-62. 23.

20. Prokofyeva E, Wegener A, Zrenner E. CataractprevalenceandpreventioninEurope:aliteraturere view.ActaOphthalmologica.2012; 91(5):395-405.

21. Gus PI, Zelanis S, Marinho D, Kunzler AL, Nicola F, Folle $\mathbf{H}$, et al. Pre-SenileCataract in Diabetic Patients: Prevalence and Early Diagnosis. Journal of Clinical Trials, 2017; 07(02): 44-67. 